\title{
How and who manage hemodialysis inpatients at national university hospitals in Japan? Based on questionnaire survey
}

Takeshi Nakata ${ }^{1,2^{*}+}$ (D), Hirotaka Shibata ${ }^{1,2}$, Yuji Kamijo ${ }^{1,3 \dagger}$ and Tsuneo Konta ${ }^{1,4 \dagger}$

\begin{abstract}
Background: More than three hundred thousand hemodialysis (HD) patients exist in Japan. The average of vintage of Japanese hemodialysis patients was longer than Western country. Longer and older hemodialysis patients tend to have various complications to be hospitalized and treated by various departments. However, the clinical management practices for HD inpatients are not well-known. In this study, we investigated the clinical management practices for HD inpatients in national university hospitals in Japan.

Methods: The questionnaire-based survey was conducted among HD management specialists of 42 national university hospitals in Japan via online correspondence or letters. This survey investigated their clinical management practices for HD inpatients of other departments. The responses were obtained from 173 (69\%) of 249 HD management specialists among 37 (90\%) of the 42 facilities.
\end{abstract}

Results: The majority (87\%) of HD management specialists were aware of the importance of medical intervention by HD specialists for the management of HD inpatients. However, only approximately $20 \%$ of HD management specialists regularly ordered blood examination and chest X-ray for the management of HD inpatients of other departments. Dialysis physicians with less experience faced more difficulty in managing HD inpatients of other departments, than experienced HD management specialists. The main reason for this difficulty was poor communication with the attending physicians, lack of management rules, and short duration of hospital stay of HD inpatients.

Conclusions: This study indicated that the clinical management practices for HD inpatients in other department were different for each HD management specialists and were affected by their clinical experience. Good communication and established inter-departmental HD management rules would be necessary.

Keywords: Hemodialysis, Hospitalist, Questionnaire survey, Practice pattern, Patient care

\footnotetext{
*Correspondence: nakata@oita-u.ac.jp

${ }^{\dagger}$ Takeshi Nakata, Yuji Kamijo and Tsuneo Konta contributed equally to this work.

'Japanese National University Hospitals' Association for Blood Purification

Divisions, Tokyo, Japan

2Department of Endocrinology Metabolism, Rheumatology and Nephrology,

Faculty of Medicine, Oita University, 1-1 Idaigaoka, Hasama-machi Yufu, Oita 879-5593, Japan

Full list of author information is available at the end of the article
}

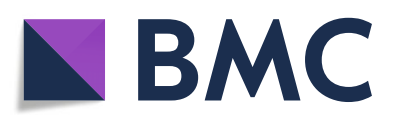

(- The Author(s). 2021 Open Access This article is licensed under a Creative Commons Attribution 4.0 International License, which permits use, sharing, adaptation, distribution and reproduction in any medium or format, as long as you give appropriate credit to the original author(s) and the source, provide a link to the Creative Commons licence, and indicate if changes were made. The images or other third party material in this article are included in the article's Creative Commons licence, unless indicated otherwise in a credit line to the material. If material is not included in the article's Creative Commons licence and your intended use is not permitted by statutory regulation or exceeds the permitted use, you will need to obtain permission directly from the copyright holder. To view a copy of this licence, visit http://creativecommons.org/licenses/by/4.0/ The Creative Commons Public Domain Dedication waiver (http://creativecommons.org/publicdomain/zero/1.0/) applies to the data made available in this article, unless otherwise stated in a credit line to the data. 


\section{Introduction}

The number of hemodialysis (HD) patients is growing all over the world [1]. Because of the advancement of HD techniques, tools, systems, and various new drugs, the prognosis of patients requiring HD has improved. Patients requiring $\mathrm{HD}$, including elderly patients, often undergo various types of surgeries, especially for cardiovascular diseases [2]. HD inpatients are ordinarily managed by a variety of specialists to treat complications that require hospitalization.

Recently, the important role of the "hospitalist" for inpatient care has been reported. A hospitalist is a licensed physician who practices in a hospital and treats a variety of illnesses and injuries. HD management specialists are expected to play the role of "hospitalist" through the managing of the general condition of HD inpatients. There are some reports that the nephrologist's involvement in the ICU unit may improve patients' prognosis $[3,4]$.

There are several large cohort studies on the practice pattern of HD outpatients in the world, including the Dialysis Outcomes and Practice Patterns Study (DOPPS study) [5]. Further, in Japan, the J-DOPPS (the Japanese-Dialysis Outcomes and Practice Patterns) and Japanese Society for Dialysis Therapy (JSDT) registries have published some useful reports about practice patterns, ESA management, vascular

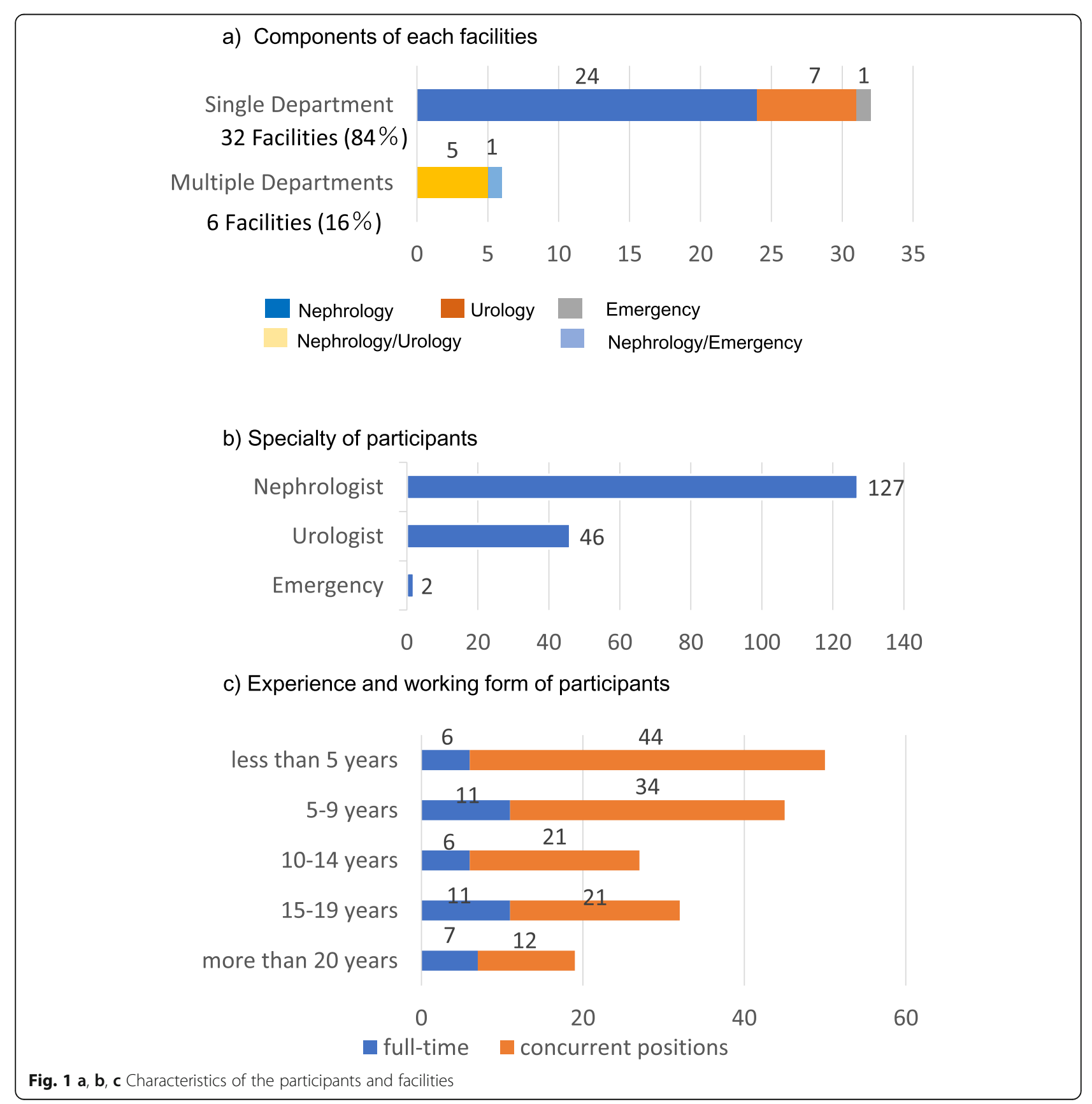




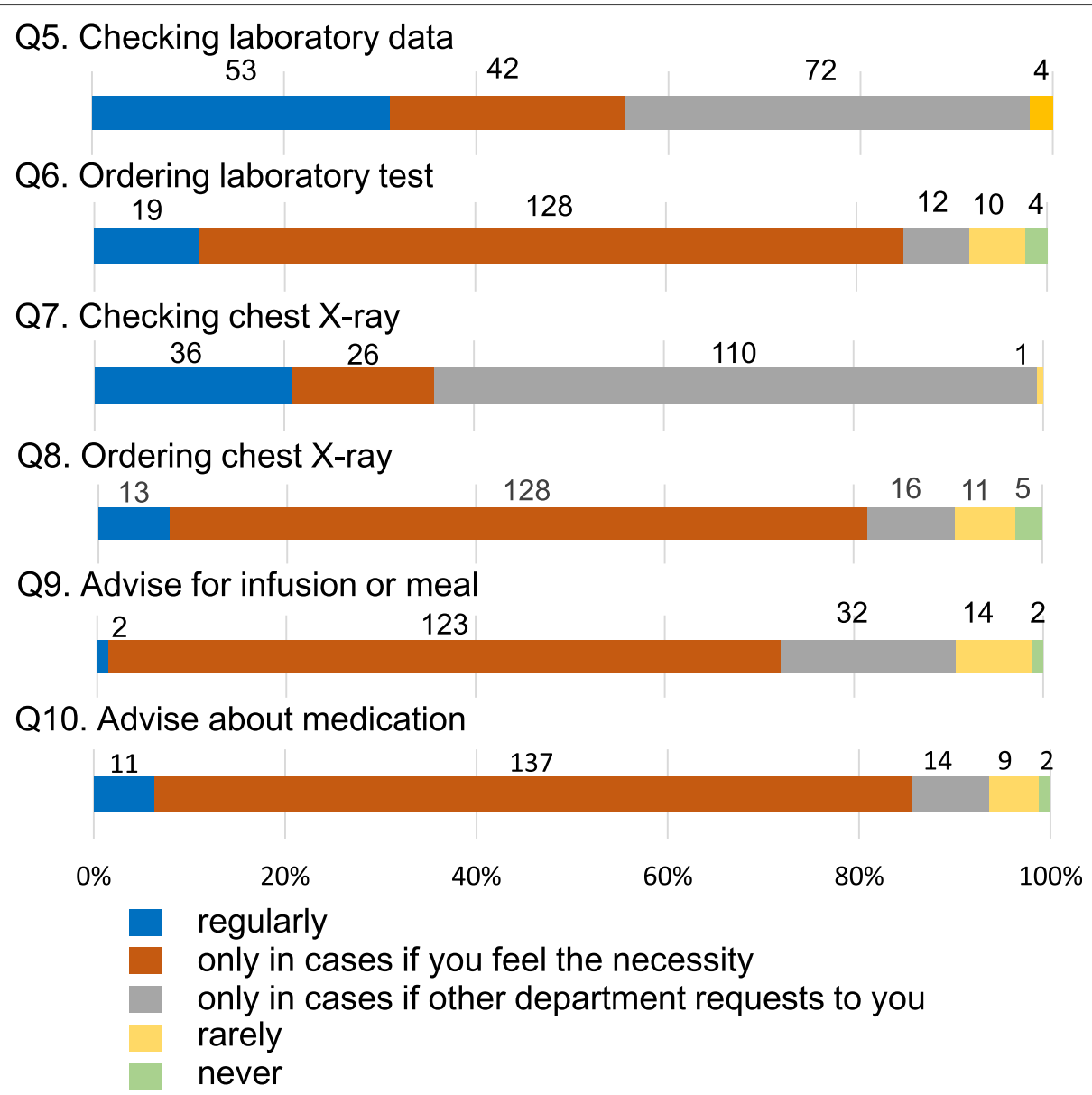

Fig. 2 Clinical practice pattern at the dialysis center. Responses for questions 5 to 10. Each question is listed below. Responses were 5 th grade of Likert-scale. Question 5: How often do you check laboratory data of other departments' inpatients on hemodialysis when you are on duty at the hemodialysis center? Question 6: How often do you order blood examination for other departments' inpatients on hemodialysis when you are on duty at the hemodialysis center? Question 7: How often do you order blood examination for inpatients on hemodialysis at other departments? Question 8: How often do you order chest X-ray for inpatients on hemodialysis at other departments when you are on duty at the hemodialysis center? Question 9: How often do you advise the physician responsible at other departments for inpatients on hemodialysis about the patient's fluid or food as nutrition when you are on duty at the hemodialysis center? Question 10: How often do you advise the physician responsible for inpatients on hemodialysis at other departments about the medication (especially phosphate binder) when you are on duty at the hemodialysis center?

Q4. Manual/rules to treat HD inpatients of other departments yes 104

no 69

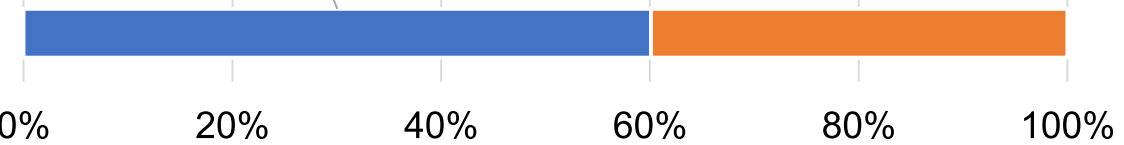

Fig. 3 The responses of question 4. Question 4: Does your HD center have a manual or rules to treat the HD inpatients of other departments? Responses were "Yes" or "No" 
access, CKD-MBD, and modality [6, 7]. However, the actual clinical management practices for HD inpatients of other departments are not well-known.

Critically ill patients requiring HD with multiple complications are often referred to the large general hospitals. The Japanese national university hospitals are large general hospitals and exist in almost all prefectures in Japan. To identify the management practices for HD inpatients, we conducted a questionnaire survey at all the 42 national university hospitals in Japan.

\section{Methods}

This study was a cross-sectional study conducted from August to November 2018. The subjects of this study were all physicians who managed HD at the HD centers in the 42 national university hospitals in Japan. We sent an email requesting cooperation with the survey to all of the representatives of the HD centers to ask them to encourage all HD management physicians to complete this questionnaire survey via online or a letter.

The items of the questionnaire included physicians' characteristics (specialty, experience, and working form), management of procedures ordered by the other departments (blood examination, chest X-ray, fluid, and nutrition), a rule for management of HD inpatients of other departments, and physician's opinion regarding management of HD inpatients of other departments. The ethical committee of Oita University approved this survey (approval number 1377).

\section{Statistical analysis}

We conducted an ordinal logistic regression analysis to determine the factors associated with dialysis physician's practice patterns or their feeling. This analysis included various factors such as physician's characteristics (experience and working form) and facilities' characteristics (rules for managing HD inpatients of other departments, HD management by a single department or multiple departments). A $p$-value $<0.05$ was considered statistically significant. JMP (Ver 13.2.1) was used in this study.

\section{Results}

All 42 facilities agreed to participate in this questionnaire survey. The responses were obtained from 173 (69\%) of 249 HD management specialists among 37 (88\%) of the 42 facilities. The response rate of the letters and the e-mail was 54.8 and $84.0 \%$, respectively.

\section{Characteristics of facilities}

Thirty-one HD centers (84\% of 37 centers) were managed by the physicians from a single department $($ nephrology $=24$, urology $=6$, emergency $=1)$, whereas
6 HD centers (16\%) were managed by physicians from two departments (nephrology and urology $=5$, nephrology and emergency = 1) (Fig 1a).

Characteristics of participants (questions 1, 2, 3-1, 4-1, 4-2) We asked for characteristics of participants in question 1 to question 3, like specialty and experiences. In this survey, 127 Nephrologists, 46 Urologist and 2 Emergency doctors responded (Fig. 1b) Among the 173 HD management specialists, the number of physicians working at the HD centers for less than 5 years, 5-9 years, $10-14$ years, $15-19$ years, and more than 20 years was $50(29 \%), 45(26 \%), 27(16 \%), 32(18 \%)$, and 19 (11\%), respectively. Forty-one physicians (24\%) were working full-time at HD centers, whereas the remaining 132 physicians (76\%) were working at both the HD center and in other departments (Fig. 1c).

\section{Practice pattern (questions 5-10)}

Concerning managing HD inpatients of other department, only $31 \%$ of $\mathrm{HD}$ management specialists regularly check laboratory data and only $21 \%$ of HD management specialists regularly check chest X-ray (Fig. 2). In addition, the percentage of ordering laboratory test or chest X-ray by HD management specialists was less than $20 \%$. Most of HD management specialists advise for meal and medication of HD inpatients of other departments only when they asked for or they feel necessity (Fig. 2).

Table 1 The consistency (\%) of the responses to Q5-Q10 within the same facility

\begin{tabular}{lllllll}
\hline $\begin{array}{l}\text { Facilities } \\
\text { (No. of } \\
\text { physicians) }\end{array}$ & \multicolumn{6}{c}{ The consistency (\%) of the answers to the questions } \\
\cline { 2 - 7 } & Q5 & Q6 & Q7 & Q8 & Q9 & Q10 \\
\hline A (18) & 56 & 61 & 72 & 61 & 50 & 56 \\
B (12) & 42 & 42 & 67 & 58 & 83 & 67 \\
C (11) & 45 & 73 & 82 & 64 & 64 & 73 \\
D (10) & 80 & 100 & 40 & 90 & 100 & 100 \\
E (10) & 50 & 70 & 70 & 70 & 70 & 80 \\
F (9) & 33 & 78 & 78 & 89 & 67 & 89 \\
G (8) & 75 & 88 & 88 & 88 & 63 & 75 \\
H (8) & 50 & 75 & 50 & 75 & 38 & 88 \\
I (7) & 57 & 100 & 100 & 100 & 100 & 100 \\
J (6) & 67 & 67 & 67 & 50 & 100 & 100 \\
K (6) & 50 & 67 & 33 & 67 & 50 & 33 \\
L (5) & 60 & 80 & 80 & 80 & 60 & 60 \\
M (5) & 60 & 60 & 40 & 80 & 80 & 80 \\
N (5) & 40 & 100 & 60 & 100 & 100 & 100 \\
\hline
\end{tabular}

We analyzed the consistency of each response from the same facilities, which had more than four responders. Question 5 is frequency of checking laboratory data. Question 6 is frequency of ordering of laboratory data. Question 7 is frequency of checking chest X-ray. Question 8 is frequency of ordering of chest X-ray. Question 9 is frequency of advising for medication. Question 10 is frequency of advising for fluid or nutrition 
Management policy and differences in clinical practices within the same facility (question 4)

A shared management policy or rules in the facilities were made in $60 \%$ of HD management specialists (Fig. 3). Even within the same hospital, the management policy differed among individual physicians. We examined the differences between the actual practice patterns within the same facilities, where more than four physicians responded to the survey. The average consistency was approximately 40 $70 \%$ for each practice (Table 1 ).

\section{(a) Q13. Importance of dialysis physicians involvement in managing HD patient of other departments 104 \\ 46 \\ 194 \\ $0 \%$
very important \\ $40 \%$ \\ important \\ $60 \%$ \\ $80 \%$ \\ $100 \%$ \\ not so important}

(b) Q14. Feeling of difficulty for HD patients management

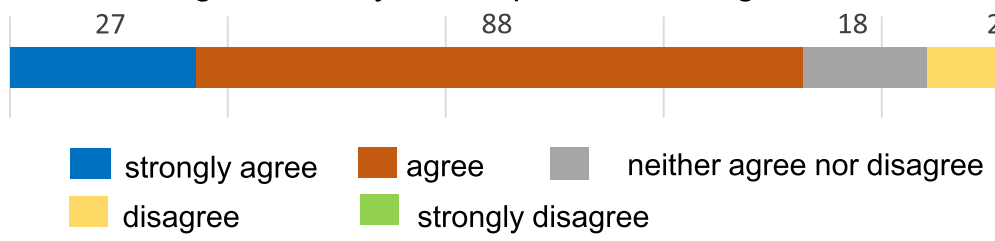

(c) Q14 analyzed by experience duration

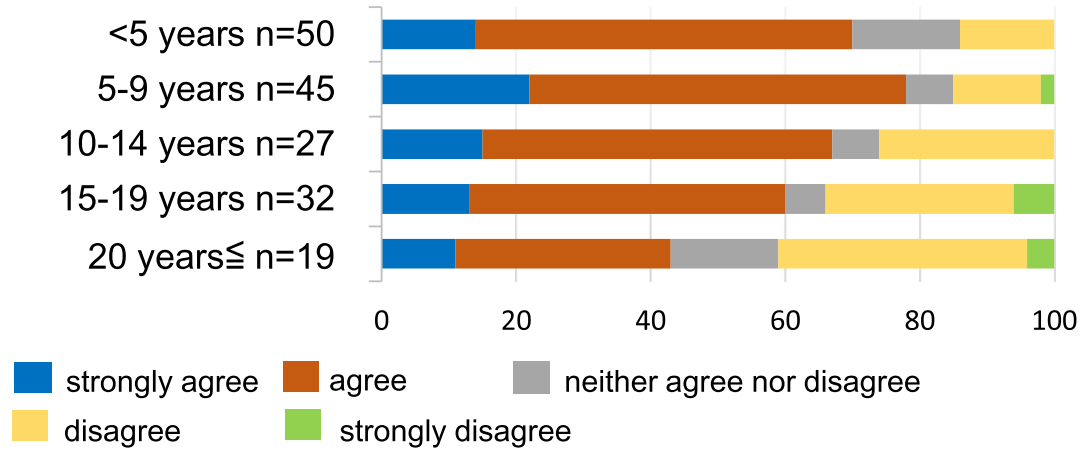

(d) Q14 analyzed by working form

$$
\begin{array}{r}
\text { concurrent positions } n=132 \\
\text { full-time } n=40
\end{array}
$$

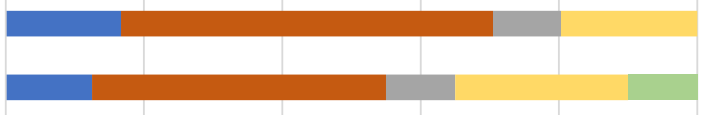

$\begin{array}{llllll}0 \% & 20 \% & 40 \% & 60 \% & 80 \% & 100 \%\end{array}$

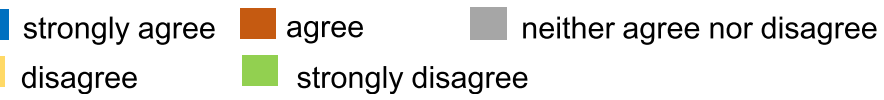

Fig. 4 Perception of dialysis physicians. a Responses for question 13. Question 13: What do you think about the importance of dialysis physician's involvement in managing HD patients of other departments? Responses were 5th grade of Likert scale (a) very important, (b) important, (c) neither agree nor disagree, (d) not so important, (e) not important. b Feeling of difficulty for management HD. Question 14: Do you feel difficulty when you manage patients with hemodialysis at other departments? Responses were (a) strongly agree, (b) agree, (c) neither agree nor disagree, (d) disagree, (e) strongly disagree. c Analyzed responses for the question above categorized by their experience for 5 years. $\mathbf{d}$ Analyzed responses for the question above categorized by working forms 
Table 2 Multivariate ordinal logistic analysis: the factors related to the difficulty in managing HD patients of other departments

\begin{tabular}{lll}
\hline Factors & Coefficient $\mathbf{( 9 5 \% ~ C l )}$ & $\boldsymbol{p}$ value \\
\hline Experience at HD center (per 5 years increase) & $-0.23(-0.45,-0.02)$ & 0.048 \\
Facility's rule in managing of HD patients of other departments (yes vs. no) & $0.28(-0.38,0.20)$ & 0.54 \\
Working full time at HD center (vs. part-time) & $-0.09(-0.07,0.62)$ & 0.11 \\
Single department (vs. multiple departments) & $-0.22(-0.57,0.12)$ & 0.21 \\
\hline
\end{tabular}

This analysis included multiple factors such as physician's characteristics (department, experience by 5 years, and working form) and facilities' characteristic (rules for managing HD inpatients of other departments and HD management by single or multiple departments)

Cl confidence interval

The perception of HD management physicians (questions 13-15)

Eighty-seven percent of HD management specialists were aware of the importance of medical intervention by HD specialists for the management of HD inpatient (Fig. 4a). Most physicians find it difficult or think it to be a burden when managing HD inpatients in other departments, and the physicians with lesser experience faced more difficulty than experienced physicians (Fig. 4b, c). After adjusting four independent variables (single/multiple departments), working style (full-time/part-time in HD center), duration of HD experience (by five years), and having shared rules (yes/no), physician's experience was significantly associated with the feeling of difficulty in the management of HD inpatients in other departments (Table 2). The main reason for this difficulty was poor communication with attending physicians of the other department, lack of management rules, and short duration of hospital stay of HD patients (Fig. 5).

\section{Discussions}

The current study showed that the physicians working at the HD centers in Japanese university hospitals were mainly nephrologists and urologists. Approximately two-thirds of them worked at both the HD center and their primary department (nephrology or urology). More than $60 \%$ facilities had a management policy of HD inpatients shared among HD management specialists. Even the practice patterns of HD management (checking laboratory data, chest X-ray, and medication) within the same facilities differed among individual physicians. The feeling of difficulty in the management of HD inpatients of other departments was significantly correlated with the physician's experience in HD management.

Some reports by using big data showed that HD patients have a higher mortality risk after surgery than non-dialysis patients $[8,9]$. The reason for this is that HD patients tend to have multiple comorbidities, including cardiovascular disease, hypertension, diabetes mellitus, and compromised status because of their old age and frailty state $[10,11]$. The HD management specialists treating HD inpatients should monitor the dosage of various drugs, the contents of infusion fluids, and nutrition. For the prevention of complications after surgery, it is vital that HD management specialists should involve in HD patients' treatment, even if they are treated in other departments.

In Japan, a general hospitalist recently plays an essential role in caring for critically ill inpatients [12]. They can save medical costs and manage patients' care well with co-managing physicians in other departments [13]. We believed that HD management specialists are a general hospitalist for HD patient care. Therefore, active intervention by HD management specialists is important for the prognosis of HD patients. However, several studies reported that some "barriers" hinder good collaboration between general hospitalist and co-managing

\section{a) the different department b) no specific way to communicate c) no regular conference d) the short hospital stay e) others}

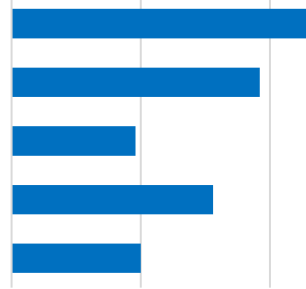

\section{(n) $0 \quad 25 \quad 50 \quad 75 \quad 100$}

Fig. 5 Responses for question 15. Question 15: Choose the reason why you feel difficulty in managing inpatients with hemodialysis at other departments? (You can choose more than response) Responses were (a) because of the different divisions, (b) because of no specific way to communicate with the other department, (c) because of no regular conference with the other department, (d) because of the short duration of hospital stay of such patients, (e) others 
physicians in other departments because of limited conference time and/or lack of positive interpersonal interactions, such as having worked together previously [14] . The current study indicated that the clinical experience of the dialysis physician influenced their feeling burdened with HD management. Abundant clinical experience may remove the "barriers" between the HD management specialists and the co-managing physicians in other departments. To reduce the burden on HD management specialists regardless of their clinical experience, standardized manuals, or unified treatment policies within the facility, would be needed. However, $60 \%$ of the study facilities had shared management policy among physicians. Only $11 \%$ and $7.5 \%$ of physicians regularly order laboratory data and chest X-ray. Fiftyfive percent and $36 \%$ physicians check laboratory data and chest X-ray regularly or only when if they feel necessity. This means actual practice pattern differs from each physician, and the involvement of the HD management physicians might be affected by their motivations. Even in the same facilities, the responses for each practice patterns were different from 40 to $70 \%$ in this study. This situation may make HD management specialists face difficulty in HD management.

This study has several limitations. First, this is a questionnaire-based study where physicians voluntarily participated, and only national university hospitals participated. Therefore, there might be a selection bias. Caution is required to generalize the findings. Second, this study was based on a questionnaire survey, and thus, the actual practice pattern might not be the same as those demonstrated by the responses. Third, we did not collect the gender of participants, so we cannot analyze gender differences. Despite these limitations, this study has some strengths. First, this is the first survey clarifying the clinical management practices of physicians for HD inpatients. Second, the response rate of this survey from HD management specialists was very high, and questionnaire responses were obtained from all physicians involved in HD management in all national university hospitals throughout Japan. These advantages make the results of the study reliable.

In conclusion, the clinical management practices for HD inpatients in other departments were different for each physician involved in HD management. The physician's clinical experience might affect their HD management. For a good prognosis of HD inpatients, good communication and established interdepartmental HD management rules appear to be necessary. We recommend that all facilities having an HD center make efforts to establish manuals and rules to standardize management practices for HD management specialists.

\section{Supplementary Information}

The online version contains supplementary material available at https://doi. org/10.1186/s41100-021-00329-9.

Additional file 1: Supplementary table 1. The questionnaire: questions and answers.

\section{Abbreviations}

HD: Hemodialysis; DOPPS study: Dialysis Outcomes and Practice Patterns Study; ESA: Erythropoiesis-stimulating agent; JSDT: Japanese Society for Dialysis Therapy; CKD-MDB: Chronic kidney disease-mineral and bone disorder

\section{Acknowledgements}

This study was supported by the Grants-in-Aid for Scientific Research (16K06175). We would like to thank Editage (www.editage.com) for English language editing. All data were double-checked by Takeshi Nakata and Tamami Nakayama. We also thank all participants of this study, and we wrote the representative of each facilities, Akita University, Shintaro Narita; Asahikawa Medical University, Motoki Matsuki; Chiba University, Noriyuki Hattori; Ehime University, Tadahiko Kikugawa; Gifu University, Soichiro Nagaya; Gunma University, Yoshitaka Sekine; Hamamatsu University School of Medicine, Sayaka Ishigaki; Hiroshima University, Shigehiro Doi; Hokkaido University, Daiki Iwami; Kagawa University, Tadashi Sofue; Kanazawa University, Kengo Furuichi; Kobe University, Keiji Kono; Kochi University, Shingo Ashida; Kumamoto University, Kazuhiko Nishi; Kyoto University, Takeshi Matsubara; Kyushu University, Kiichiro Fujisaki; Mie University, Eiji Ishikawa; Nagasaki University, Yasushi Mochizuki; Nagoya University, Shoji Saito; Niigata University, Suguru Yamamoto; Okayama University, Katsuyuki Tanabe; Saga University, Motoaki Miyazono; Shiga University, Masami Kanasaki; Shimane University, Hiroaki Shiina; Shinshu University, Yuji Kamijo; The University of Tokyo, Yoshifumi Hamasaki; Tokushima University, Kojiro Nagai; Tokyo Medical and Dental University, Tomokazu Okado; Tottori University, Chishio Munemura; University of Fukui, Kenji Kasuno; University of Miyazaki, Hiroko Inagaki; University of the Ryukyus, Kojiro Kinjyo; University of Toyama, Hidenori Yamazaki; University of Tsukuba, Kunihiro Yamagata; University of Yamanashi, Mizuya Fukasawa; Yamagata University, Tsuneo Konta; and Yamaguchi University, Koki Fujikawa.

\section{Authors' contributions}

TN designed this study. YK and TK approved study design. TN mainly carried out this survey. TN, YK, and KT analyzed the data. TN drafted the article. YK and TK revised it. YK and TK provided intellectual content of critical importance to the work described. HS gave final approval of the version to be published. The authors read and approved the final manuscript.

Funding

Grants-in-Aid for Scientific Research (16K09175).

\section{Availability of data and materials}

The datasets used and/or analyzed during the presents study are available from the corresponding author on reasonable request.

\section{Ethics approval and consent to participate}

The ethics committee of Oita University approved this study. We did not collect individual information. The study protocol adhered to the guideline stipulated in the Helsinki Declaration and Clinical Trials Act made by the Ministry of Health, Labour, and Welfare in Japan. The research purpose was made known to participants before the survey. They were informed that their answering the survey would be regarded as informed consent.

\section{Consent for publication}

We have obtained consent to publish from the participant.

\section{Competing interests}

The authors declare no competing interests.

\section{Author details}

'Japanese National University Hospitals' Association for Blood Purification Divisions, Tokyo, Japan. ²Department of Endocrinology Metabolism, Rheumatology and Nephrology, Faculty of Medicine, Oita University, 1-1 
Idaigaoka, Hasama-machi Yufu, Oita 879-5593, Japan. ${ }^{3}$ Department of Nephrology, Shinshu University School of Medicine, 3-1-1, Asahi, Matsumoto 390-8621, Japan. ${ }^{4}$ Department of Public Health and Hygiene, Yamagata University Graduate School of Medicine, 2-2-2, lida-Nishi, Yamagata 990-9585, Japan

Received: 27 November 2020 Accepted: 7 February 2021

Published online: 24 March 2021

\section{References}

1. Wetmore JB, Collins AJ. Global challenges posed by the growth of endstage renal disease. Ren Replace Ther. 2016;2:15.

2. Taamallah K, Sahraoui S, Ghodhbane W, Messaoudi H, Ziedi M, Lajmi M, Chenik S. Particularities of cardiac surgery in chronic hemodialysis patients. Tunis Med. 2017:95:353-9.

3. Charytan C, Kaplan AA, Paganini EP, Weiss J, Owen WF Jr. Role of the nephrologist in the intensive care unit. Am J Kidney Dis. 2001;38:426-9.

4. Askenazi DJ, Heung M, Connor MJ Jr, Basu RK, Cerdá J, Doi K, Koyner JL, Bihorac A, Golestaneh L, Vijayan A, Okusa MD, Faubel S, American Society of Nephrology Acute Kidney Injury Advisory Group. Optimal role of the nephrologist in the intensive care unit. Blood Purif. 2017;43:68-77.

5. Dialysis outcomes and practice patterns study; URL ; https://www.dopps. org/AboutUs.aspx. Accessed 10 Nov 2020.

6. Hanafusa N, Nomura T, Hasegawa T, Nangaku M. Age and anemia management: relationship of hemoglobin levels with mortality might differ between elderly and nonelderly hemodialysis patients. Nephrol Dial Transplant. 2014;29:2316-26.

7. Asano M, Thumma J, Oguchi K, Pisoni RL, Akizawa T, Akiba T, Fukuhara S, Kurokawa K, Ethier J, Saran R, Saito A, J-DOPPS Research Group. Vascular access care and treatment practices associated with outcomes of arteriovenous fistula: international comparisons from the Dialysis Outcomes and Practice Patterns Study. Nephron Clin Pract. 2013;124:23-30.

8. Shinkawa $\mathrm{H}$, Yasunaga $\mathrm{H}$, Hasegawa $\mathrm{K}$, et al. Mortality and morbidity after pancreatoduodenectomy in patients undergoing hemodialysis: analysis using a national inpatient database. Surgery. 2019;165:747-50

9. Shinkawa H, Yasunaga H, Hasegawa K, Matsui H, Michihata N, Fushimi K, Kokudo N. Mortality and morbidity in dialysis-dependent patients undergoing spinal surgery: analysis of a national administrative database in Japan. J Bone Joint Surg Am. 2012;94:433-8.

10. Nitta K, Hanafusa N, Tsuchiya K. Role of frailty on outcomes of dialysis patients. Contrib Nephrol. 2018;195:102-9.

11. Kan W-C, Wang J-J, Wang S-Y, Sun Y-M, Hung C-Y, Chu C-C, Lu C-L, Weng S-F, Chio C-C, Chien C-C. The new comorbidity index for predicting survival in elderly dialysis patients: a long-term population-based study. PLoS One. 2013;8:e68748

12. Hamada O, Tsutsumi T, Tsunemitsu A, Fukui T, Shimokawa T, Imanaka Y. Impact of the hospitalist system in Japan on the quality of care and healthcare economics. Intern Med. 2019:58:3385-91.

13. Salim SA, Elmaraezy A, Pamarthy A, Thongprayoon C, Cheungpasitporn W, Palabindala V. Impact of hospitalists on the efficiency of inpatient care and patient satisfaction: a systematic review and meta-analysis. J Community Hosp Intern Med Perspect. 2019;9:121-34.

14. Adams TN, Bonsall J, Hunt D, Puig A, Richards JB, Yu L, McSparron JI, Shah $\mathrm{N}$, Weissler J, Miloslavsky EM. Hospitalist perspective of interactions with medicine subspecialty consult services. J Hosp Med. 13(5):318-23.

\section{Publisher's Note}

Springer Nature remains neutral with regard to jurisdictional claims in published maps and institutional affiliations.

Ready to submit your research? Choose BMC and benefit from:

- fast, convenient online submission

- thorough peer review by experienced researchers in your field

- rapid publication on acceptance

- support for research data, including large and complex data types

- gold Open Access which fosters wider collaboration and increased citations

- maximum visibility for your research: over $100 \mathrm{M}$ website views per year

At BMC, research is always in progress.

Learn more biomedcentral.com/submissions 